\title{
Continuous monitoring of an earth fissure in Chino, California, USA - a management tool
}

\author{
M. C. Carpenter \\ formerly at: U.S. Geological Survey, Tucson, Arizona, USA \\ Correspondence to: M. C. Carpenter (mccarp@dakotacom.net) \\ Published: 12 November 2015
}

\begin{abstract}
Continuous measurements of deformation have been made in Chino, California across an earth fissure and nearby unfissured soil since 2011 in two buried, horizontal, $150 \mathrm{~mm}$ pipes, $51 \mathrm{~m}$ long, which are connected by sealed boxes enclosing vertical posts at mostly $6 \mathrm{~m}$ intervals. Horizontal displacements and normal strain are measured in one line using nine end-to-end quartz tubes that are attached to posts and span fissured or unfissured soil. The free ends of the tubes are supported by slings and move relative to the attachment post of the next quartz tube. Linear variable differential transformer (LVDT) sensors measure the relative movements. Five biaxial tilt sensors were also attached to selected posts in that line. Relative vertical movement was measured at nine locations along the line in the second pipe using low-level differential pressure sensors. The second pipe is half full of water giving a free water surface along its length. Data are recorded on a Campbell CR10 using multiplexers.

The quartz-tube horizontal extensometers have exhibited more than $3 \mathrm{~mm}$ of predominantly elastic opening and closing in response to about $32 \mathrm{~m}$ of seasonal drawdown and recovery, respectively, in an observation well $0.8 \mathrm{~km}$ to the south. The nearest production well is $1.6 \mathrm{~km}$ to the west. The horizontal strain was $5.9 \times 10^{-5}$ or $30 \%$ of the lowest estimate of strain-at-failure for alluvium. Maximum relative vertical movement was $4.8 \mathrm{~mm}$. Maximum tilt in the fissure zone was 0.09 arcdeg while tilt at a separate sensor $100 \mathrm{~m}$ to the east was 0.86 arcdeg, indicating a wider zone of deformation than is spanned by the instrumentation. High correlation of horizontal displacements during drawdown, and especially recovery, with change in effective stress supports differential compaction as the mechanism for earth-fissure movement.

The continuous measurements of horizontal strain coupled with water-level fluctuations and vertical borehole extensometry can provide a real-time adaptive management tool for restricting pumping if strain approaches the lower limit of strain-at-failure or a stress-strain curve deviates from the previous mostly elastic regimen.
\end{abstract}

\section{Introduction}

A zone of earth fissures opened as early as 1974 on the California Institute for Men prison in Chino, California. Renewed fissuring occurred in 1991 on prison grounds and northward for $1.6 \mathrm{~km}$ in a zone as much as $150 \mathrm{~m}$ wide (Stewart et al., 1998). In the 1990s, the fissure split a house and drained a liquid manure pond at a dairy, possibly directly contaminating the shallow aquifer. The house was condemned and destroyed. As a result of management of groundwater pumping by the Chino Basin Watermaster, fissuring has been minimal since the 1990s and limited to asphalt parking lots and vacant properties. The structural setting of the Chino earth fis- sure is a north-south, strike-slip, fault-zone, groundwater barrier that bounds a subsidence bowl to the west and concentrates differential subsidence over a limited horizontal distance (Wildermuth Environmental, 2007).

\section{Instrumentation}

In October 2011, instruments were installed in a west to east line at 5500 Daniels St., Chino, California, in a vacant lot, which had been the location of the dairy and destroyed house (Fig. 1). The instruments provide a continuous record of horizontal displacements, differential vertical movement, 
and tilt across the earth fissure and nearby unfissured soil. Two buried, horizontal, $150 \mathrm{~mm}$ pipes, $51 \mathrm{~m}$ long, are connected by sealed boxes enclosing vertical, $3-\mathrm{m}$, grounding rod posts driven into the ground at mostly $6 \mathrm{~m}$ intervals. Data are recorded on a Campbell CR10 datalogger using multiplexers.

Horizontal displacements are measured in one line using nine end-to-end quartz tubes that are attached to posts and span fissured or unfissured soil. Tubes are $15 \mathrm{~mm}$ OD, $13 \mathrm{~mm}$ ID. Trans-Tek $\pm 6 \mathrm{~mm}, 0242-0000$ linear variable differential transformer (LVDT) sensors measure the relative displacements. The free ends of the tubes are supported by beadedchain slings and move relative to the attachment post of the next quartz tube. A tube is attached to a post by means of an aluminum strip that extends behind the end of its attachment post, and the LVDT is attached to a nonmagnetic stainless steel strip that extends beyond the end of its post. The length of aluminum times its coefficient of expansion $\left(2.4 \times 10^{-5}{ }^{\circ} \mathrm{C}^{-1}\right)$ plus the length of stainless steel times its coefficient of expansion $\left(1.2 \times 10^{-5}{ }^{\circ} \mathrm{C}^{-1}\right)$ equals the length of quartz times its coefficient of expansion $\left(5.7 \times 10^{-7}{ }^{\circ} \mathrm{C}^{-1}\right)$. This compensating design reduces temperature effects by as much as an order of magnitude.

Relative vertical movement was measured at nine locations along the line in the second pipe using Honeywell Micro Switch 24PCEFA6D $\pm 34 \mathrm{hPa}( \pm 0.5 \mathrm{psi})$ low-level differential pressure sensors. Differential silicon-strain-gage pressure sensors exhibit a voltage shift in response to a pressure change common to both ports. For low-level sensors used for high precision, a secondary common-mode calibration must be done over the range of barometric-pressure change. An adjustment can be applied or sensors can be selected with identical shifts. The second pipe is half full of water giving a free water surface along its length.

Five Applied Geomechanics (now Jewell Instruments) 902-TH biaxial tilt sensors were attached to selected posts in the quartz-tube line. Temperature sensors incorporated in the tilt sensors provided the temperature measurements for the instrument enclosures. Biaxial tilt sensors provide the easiest information for the extent to which deformation is restricted to a vertical plane orthogonal to the fissure.

\section{Results}

From west to east the quartz-tube spans are designated Q1Q3, Q11, and Q4-Q8 (Fig. 2). Q11 spans the historical fissure zone. Curves represent cumulative displacement along the line. For example, Q8 is the sum of all displacements Q1-Q8. The quartz-tube horizontal extensometers have exhibited more than $3 \mathrm{~mm}$ of predominantly elastic opening and closing in response to about $32 \mathrm{~m}$ of seasonal drawdown and recovery, respectively, in an observation well $0.8 \mathrm{~km}$ to the south. The nearest production well is $1.6 \mathrm{~km}$ to the west, screened in a deep confined aquifer at depths of 91-

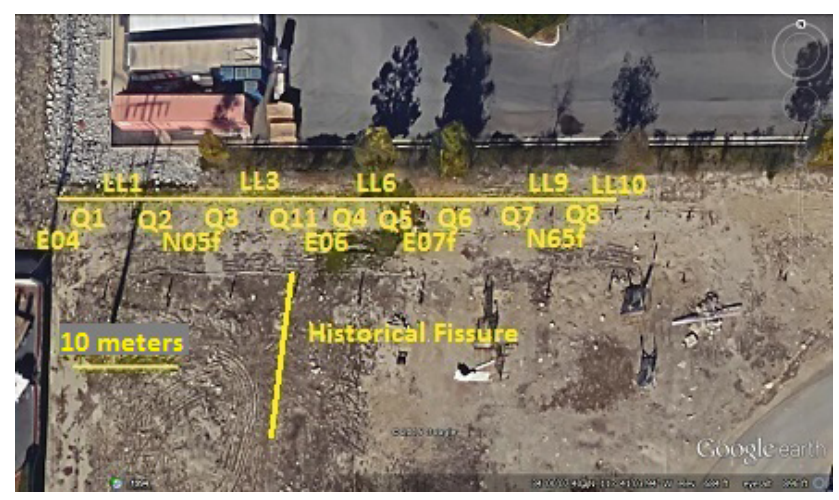

Figure 1. Instrument layout at 5500 Daniels horizontal extensometer site, Chino, California. Q1-Q8 are quart-tube horizontal extensometers. LL1-LL10 are liquid-level sensors. E04-N65f are biaxial tilt sensors.

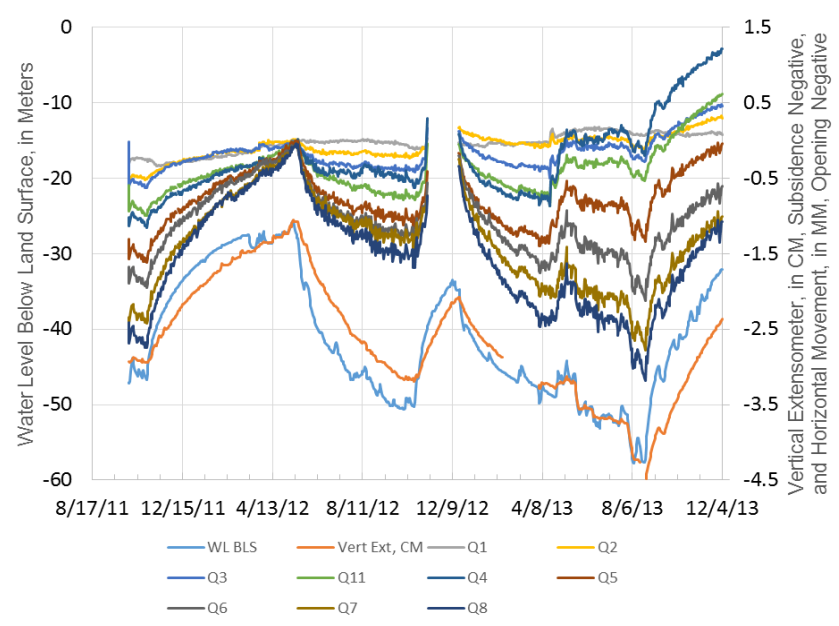

Figure 2. Quartz-tube horizontal movement compared with waterlevel fluctuation in an observation well and deep-extensometer compaction $0.8 \mathrm{~km}$ to the south.

$140 \mathrm{~m}$ and $152-298 \mathrm{~m}$. The horizontal strain was $5.9 \times 10^{-5}$ or $30 \%$ of the lowest estimate of strain-at-failure for alluvium (Jachens and Holzer, 1982).

Coefficients of determination for the pairs water-level decline and deep extensometer, water-level decline and horizontal displacements (Q8), and deep extensometer and horizontal displacements (Q8) range from 0.89 to 0.99 (Table 1). The lower correlation between horizontal displacements and both water-level decline and the deep extensometer during drawdown 2013 reflects closing of and major deviation of span Q4 during that period.

The deviation of span Q4 began during drawdown 2012 when that span closed while spans to the east of Q5 opened uniformly. That deviation indicates concentration of fissure opening across span Q5. A much larger closing across Q4 occurred during drawdown beginning in April 2013. That closing, little movement across spans Q1 and Q2, and fairly 
Table 1. Coefficients of determination for periods of recovery and drawdown for water-level fluctuations, deep extensometer compaction, and horizontal movements.

\begin{tabular}{llll}
\hline & $\begin{array}{l}\text { Water-level } \\
\text { decline } \\
\text { and deep } \\
\text { extensometer }\end{array}$ & $\begin{array}{l}\text { Water-level } \\
\text { decline and } \\
\text { horizontal } \\
\text { movements }\end{array}$ & $\begin{array}{l}\text { Deep } \\
\text { extensometer } \\
\text { and horizontal } \\
\text { movements }\end{array}$ \\
\hline Recovery winter 2011-2012 & 0.93 & 0.95 & 0.99 \\
Drawdown 2012 & 0.95 & 0.97 & 0.93 \\
Drawdown 2013 & 0.95 & 0.89 & 0.89 \\
Recovery winter 2013 & 0.98 & 0.97 & 0.98 \\
\hline
\end{tabular}

uniform opening and closing across spans Q3, Q11, and Q5Q8 indicates that most fissure movement was concentrated across span Q5, at least $6 \mathrm{~m}$ east of the historic fissure zone, Q11.

The liquid-level, vertical-movement instrumentation is a work in progress. Sensors were built using the wire bundle of the cable as the vent tube. This technique had worked exceptionally well in the past, but excessive noise existed in the liquid-level data, presumably because of tight bends in the cable restricting pressure equalization in the reference side of the sensors. Venting the pipe to the atmosphere, piercing the cable, and inserting a syringe needle with a compliant diaphragm (sandwich bag) improved five of the sensors, LL1, LL3, LL6, LL9, and LL10. Movement of the other sensors is with respect to LL1 (Fig. 3).

The relation between liquid-level sensors and water-level fluctuation is not clearly defined. Maximum relative vertical movement was $4.7 \mathrm{~mm}$ at LL3. During drawdown 2012 all sensors exhibited uplift with respect to LL1, and LL3 reversed during late drawdown. During drawdown 2013, LL6, LL9, and LL10 exhibited similar reversing movement during early drawdown followed by decline during late drawdown, and LL3 experienced uplift delayed by more than 4 months. In contrast with horizontal strain, vertical movement in the liquid level sensors is delayed with respect to water-level fluctuations. Sensors on opposite sides of the fissure generally exhibit opposite movement.

Tilt sensors exhibited response to water-level fluctuation that was delayed by about 1 month (Fig. 4). E04 and N05f on the west side tracked water level fluctuation, while E06, E07f, and N65f exhibited opposite movement. Only tilts at E04 and E07f are in the vertical plane orthogonal to the fissure. Tilts at N05f, E06 and N65f were 75, 40, and 75 arcdeg off axis, respectively.

Maximum tilt in the fissure zone was 0.09 arcdeg while tilt at a separate sensor $100 \mathrm{~m}$ to the east was 0.86 arcdeg, indicating a wider zone of deformation than is spanned by the instrumentation (Fig. 5). Tilt at Station 23 tracks waterlevel fluctuation with a 1-month delay similar to the sensors near the fissure zone.

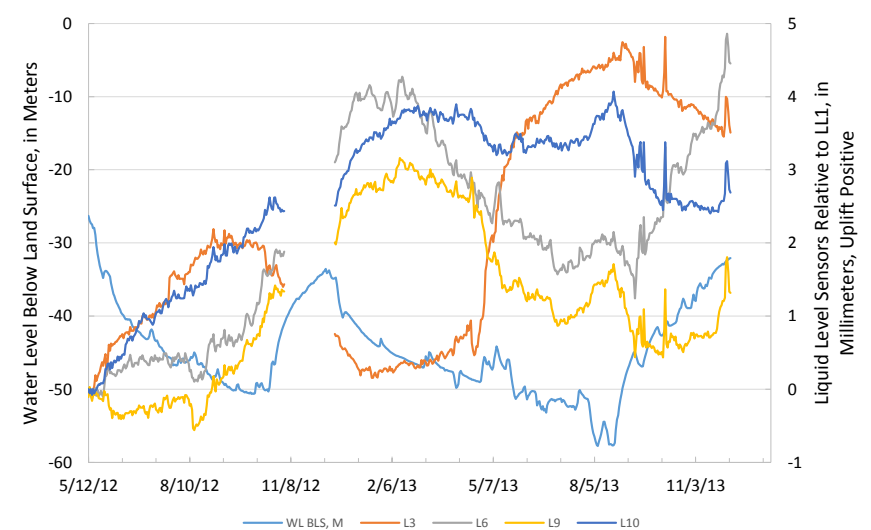

Figure 3. Vertical movement of liquid-level sensors with respect to LL1 compared with water-level fluctuation in observation well $0.8 \mathrm{~km}$ to the south. Sensor locations are in Fig. 1.

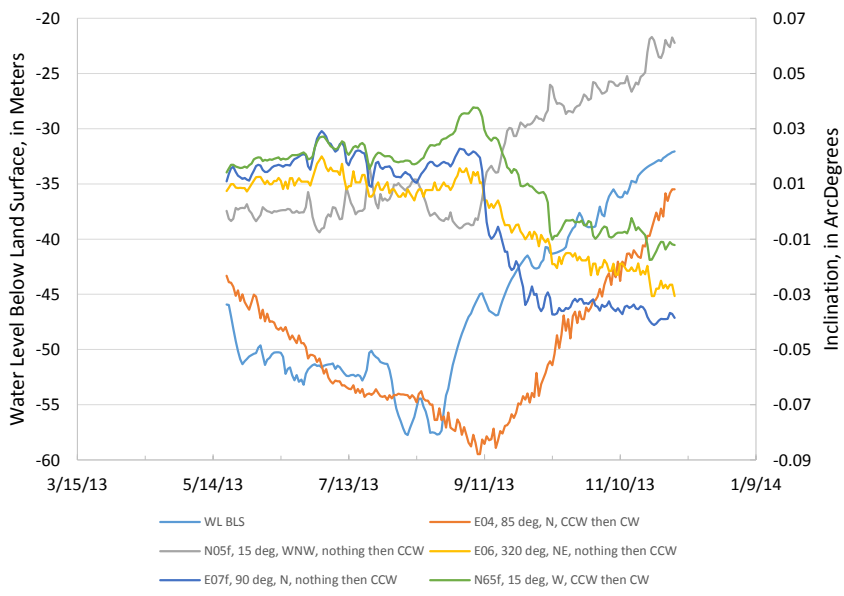

Figure 4. Biaxial tilt compared with water-level fluctuation in observation well $0.8 \mathrm{~km}$ to the south. Sensor locations are in Fig. 1. The legend gives the azimuth of the vertical plane of tilt, viewing direction, and sense of rotation for two segments of each graph. $\mathrm{CW}$ is clockwise; CCW is counterclockwise. Response to water-level fluctuation is delayed about one month and sensors on opposite sides of the fissure zone respond with the opposite sense. Only E04 and E07f exhibited tilt in the vertical plane orthogonal to the fissure.

\section{Fissure mechanisms}

Among several mechanisms proposed for earth fissuring, differential subsidence caused by differential aquifer compaction at depth remains the most substantiated (Fig. 6). Lateral change in thickness of the compressible aquifer-aquitard system, lateral change in compressibility within the system, or abrupt lateral change in water-level decline can cause fissuring. The conventional model treats the sediments overlying the zone of differential compaction as a bending plate. In that model, maximum horizontal strain is at the surface (Jachens and Holzer, 1982). Field evidence at many fissures indicates that fissures can have greater horizontal strain at 


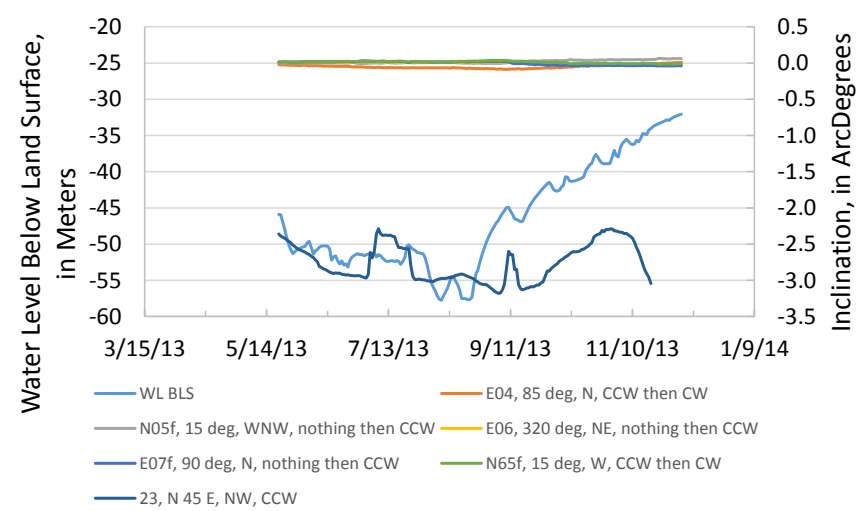

Figure 5. Biaxial tilt compared with water-level fluctuation in nearby observation well. Sensor locations are in Fig. 1. Station 23 is $100 \mathrm{~m}$ east of the fissure. The legend gives the azimuth of the vertical plane of tilt, viewing direction, and sense of rotation for two segments of each graph. CW is clockwise; CCW is counterclockwise. Deformation extends at least $100 \mathrm{~m}$ east of the fissure zone, and tilt at Station 23 is approximately ten times greater than tilt in the fissure zone.

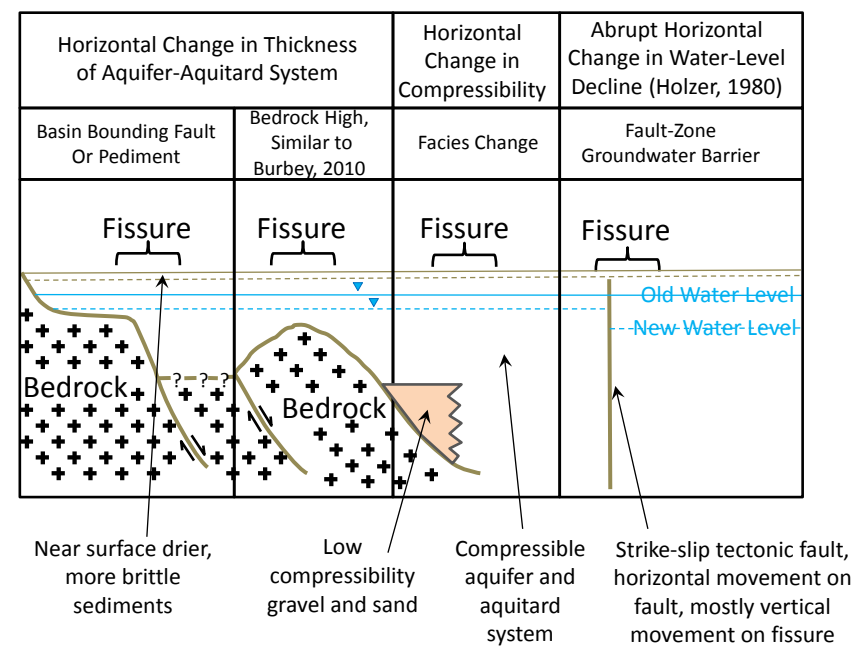

Figure 6. Schematic of differential compaction settings for earth fissures.

depth than at the surface (Carpenter, 1999). An earlier model of upward propagation of stress and strain in an elastic body (Sanford, 1959) solves this dilemma. In addition to the elastic model, Sanford performed physical experiments that demonstrate the patterns of deformation that can develop at the land surface in response to differential offset at depth (Fig. 7). High correlation of horizontal strain with change in effective stress supports differential compaction as the mechanism for earth-fissure movement.

Horizontal seepage stress is another mechanism proposed for earth fissuring (Helm, 1994). In Carpenter (1993), waterlevel fluctuations in pairs of piezometers on opposite sides of a fissure compared with horizontal strain across the fissure

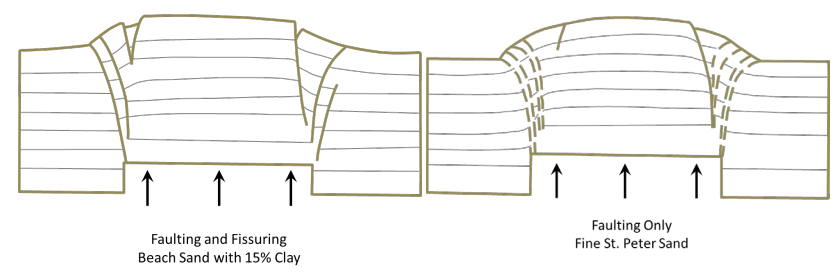

Figure 7. Results of sandbox experiments demonstrating fissuring and faulting consistent with shear and tensile failure of an elastic body exhibiting differential offset at depth (modified from Sanford, 1959 by Carpenter, 1993).

enabled a test of seepage stresses as a fissure mechanism. The coefficients of determination between water-level fluctuation in the piezometers (change in effective stress) and horizontal strain ranged from 0.83 to 0.85 , while the coefficients of determination for horizontal seepage stresses and horizontal strain ranged from 0.03 to 0.17 . In this study, coefficients of determination between water-level fluctuations and horizontal strain range from 0.89 to 0.97 (Table 1). During waterlevel recovery, fissures close (Fig. 2). Unless proponents of seepage stresses have a mechanism of water flowing back uphill during recovery dragging aquifer matrix, the mechanism of seepage stresses should be dismissed.

\section{Discussion}

The precise measurements of this study are incorporated in a larger monitoring network of semi-annual levelling and EDM with monument spacing of more than $400 \mathrm{~m}$. With error bars of $\pm 3 \mathrm{~mm}$ horizontal, the seasonal elastic deformation of about $30 \%$ of strain-at-failure would be invisible in that network. This difficulty illustrates the need for closer monument spacing and greater precision in zones of known or suspected fissuring. Monument spacing of $12 \mathrm{~m}$ would enable delimitation of a zone to be instrumented, and infilling of monuments with $2 \mathrm{~m}$ spacing would enable spacing of quartz-tube monuments.

At present, the horizontal quartz tubes are the best established technique for continuous monitoring (Davis et al., 1969; Wolff, 1970). Displacement resolution can be finer than $0.1 \mu \mathrm{m}$. Biaxial tilt sensors (Haneberg and Friesen, 1995) are the easiest to install but, as point measurements, may be the least definitive technique. The liquid-level technique adapted after Riley (1970) remains unverified by precise levelling but has great promise.

Continuous measurements of horizontal displacements using quartz tubes presents a unique method for real-time adaptive management to prevent fissure opening or reopening. Municipal groundwater pumping can be restricted if horizontal strain approaches the lower limit of strain-at-failure or, coupled with water-level fluctuations and vertical borehole extensometry, stress-strain curves deviate from the previous mostly elastic regimen. Fissures have caused catas- 
trophic damage to buildings and infrastructure. A municipal water agency that actively produces groundwater from finegrained aquifer units runs the risk of causing such damage. This monitoring tool can be used to keep their operations safely below renewed fissuring.

The clarity of response of the horizontal-displacement data demonstrates the superiority of resolution of quartz tubes over EDM surveys and the superiority of continuous measurements over periodic surveys. The seasonal elastic deformation, which constitutes a significant percentage of strain at failure would be lost in the error bars of repeated surveys.

\section{Recommendations}

Wherever both horizontal and vertical deformation have been made at earth fissures, they have been of comparable magnitude (Carpenter, 1993, 1999). Fissures termed surface faults by Holzer (1980) that have significant vertical offset can pose particular hazards. Fissure opening of as much as $25 \mathrm{~mm}$ has been documented in a few hours during major frontal storms (Carpenter, 1999). A sudden vertical offset of $50-75 \mathrm{~mm}$ in a concrete highway during a storm with limited visibility could cause a multi-vehicle accident resulting in several deaths. Repeated precise levelling and EDM surveys where known or suspected fissures cross highways would indicate locations where GPS receivers could be placed along the highway on opposite sides of the fissure. Pairs of receivers could be monitored automatically for a threshold change that would trigger a warning sign or highway closing.

Fissures have been known to close over many years. That is, monuments on opposite sides have converged in repeated surveys in addition to infilling of the void space by collapse and deposition. In many cases the closure has been accompanied by water-level recovery (Carpenter, 1999). This presents the intriguing possibility of fissure mitigation by "wait and see" or determination of a rate of water-level decline that could be sustained without causing renewed fissuring. T. Holzer's old USGS project and the old USGS Subsidence Research Project EDM and levelling measurements at numerous fissures in the Western United States could be remeasured using original instruments and state of the art instruments, located by precise GPS, and compared with longterm water-level fluctuations. Application of a Binghamsubstance model with appropriate plastic, elastic, and viscous material properties could lead to a greater understanding of long-term fissure behaviour (LSCE et al., 2014).

Fissure systems are varied and complex. Two sets of published records of continuous measurements of fissure movement have been made to date (Carpenter, 1993, and this study). As droughts lengthen and basins become more depleted, fissuring will increase. Several more sets of continuous measurements would add immensely to the understanding of fissures and increase the possibility of finding mitigating measures. In particular, comparison of fissures associ- ated with fault-zone groundwater barriers, fissures associated with known subsurface structure, and fissures without known subsurface structure would be desirable.

A study would begin with repeated EDM and levelling over monuments with $40 \mathrm{~m}$ spacing on a line $500 \mathrm{~m}$ long (LSCE et al., 2014). Deformation within that line would determine the locations of more closely spaced surveying monuments that would be used for selection of quartz-tube posts and liquid-level stations with 6-m spacing. Diameter of the quartz tubes should be increased to $18 \mathrm{~mm} \mathrm{OD}, 15 \mathrm{~mm}$ ID for improved rigidity. Permanent instrument and target monuments of $100 \mathrm{~mm}$ pipe crash posts for precise EDM would be installed beside the quartz-tube posts. Semiannual repeated precise EDM (Leica TC2003 or TDM5000) and levelling (Leica DNA03) would be compared with continuous quartz-tube horizontal displacements, liquid-level vertical movements, and tilt. Precise surveying would extend over greater lengths than the instruments providing continuous record. Surveying and continuous measurements would provide cross checks at the limit of resolution of the surveying instruments.

Acknowledgements. Funding for this work is provided by Wildermuth Environmental, Incorporated under the auspices of the Chino Basin Watermaster. Richard Wilson and Eric Lindberg provided field assistance and reviews of this paper. George Pardo also provided field assistance.

\section{References}

Burbey, T. J.: Mechanisms for earth fissure formation in heavily pumped basins, Land Subsidence, Associated Hazards and the Role of Natural Resources Development,Proceedings of EISOLS 2010, 17-22 October 2010, Queretaro, Mexico, IAHS Publ. 339, 3-8, 2010.

Carpenter, M. C.: Earth-fissure movements associated with fluctuations in ground-water levels near the Picacho Mountains, southcentral Arizona, 1980-84, U.S. Geological Survey Professional Paper 497-H, 49 pp., available at: http://pubs.usgs.gov/pp/0497h/ report.pdf, last access: 15 October 2015, 1993.

Carpenter, M. C., South-central Arizona, in: Land Subsidence in the United States, edited by: Galloway, D., Jones, D., and Ingebritsen, S., U.S. Geological Survey Circular 1182, 65-78, available at: http://pubs.usgs.gov/circ/circ1182/pdf/09Arizona.pdf, last access: 15 October 2015, 1999.

Davis, S. N., Peterson, F. L., and Halderman, A. D.: Measurement of small surface displacements induced by fluid flow, Water Resour. Res., 5, 129-138, 1969.

Haneberg, W. C. and Friesen, R. L.: Tilts, strains, and ground-water levels near an earth fissure in the Mimbres Basin, New Mexico, Geol. Soc. Am. Bull., 107, 316-326, 1995.

Helm, D. C.: Hydraulic forces that play a role in generating fissures at depth, Bulletin of the Association of Engineering Geologists, 31, 293-304, 1994. 
Holzer, T. H.: Faulting caused by groundwater level declines, San Joaquin Valley, California, Water Resour. Res., 16, 1065-1070, 1980.

Jachens, R. C. and Holzer, T. L.: Differential compaction mechanism for earth fissures near Casa Grande, Arizona, Geol. Soc. Am. Bull., 93, 998-1012, 1982.

LSCE (Luhdorff \& Scalmanini Consulting Engineers), Borchers, J. W., and Carpenter, M. C.: Land subsidence from groundwater use in California, California Water Foundation, 151 pp., available at: http://californiawaterfoundation.org/uploads/ 1397858208-SUBSIDENCEFULLREPORT_FINAL.pdf, last access: 15 October 2015, 2014.

Riley, F. S.: Land-surface tilting near Wheeler Ridge, Southern San Joaquin Valley, California, U.S. Geological Survey Professional Paper 497-G, 29 pp., 1970.
Sanford, A. R.: Analytical and experimental study of simple geologic structures: Geol. Soc. Am. Bull., 70, 19-52, 1959.

Stewart, C. A., Colby, N. D., Kent, R. T., Eagan, J. A., and Hall, N. T.: Earth fissuring, ground-water flow, and water quality in the Chino basin, California, in: Dr Joseph F. Poland symposium, Land subsidence case studies and current research: proceedings of the Dr Joseph F Poland symposium on land subsidence; 1995, Sacramento, CA, edited by: Borchers, J. W., Association of Engineering Geologists Special Publication 8, 195-205, 1998.

Wildermuth Environmental: MZ-1 Subsidence Management Plan, variously paginated, Chino Basin Watermaster, Rancho Cucamonga, California, USA, available at: http://ayala.wildermuthenvironmental.com:8888/AyalaPark/ documents/20071017_MZ1_Plan.pdf, last access: 15 October 2015, 2007.

Wolff, R. G.: Relationship between horizontal strain near a well and reverse water level fluctuation, Water Resour. Res., 6, 17211728, 1970. 